\title{
Unusual strong quasi-monochromatic ground Pc5 geomagnetic pulsations in the recovery phase of November 2003 superstorm
}

\author{
N. G. Kleimenova ${ }^{1}$, O. V. Kozyreva ${ }^{1}$, J. Manninen ${ }^{2}$, and A. Ranta ${ }^{2}$ \\ ${ }^{1}$ Institute of the Physics of the Earth RAS, B. Gruzinskaya 10, Moscow, 123995, Russia \\ ${ }^{2}$ Sodankylä Geophysical Observatory, Tähteläntie 62, FIN-99600 Sodankylä, Finland
}

Received: 10 April 2005 - Revised: 24 June 2005 - Accepted: 22 July 2005 - Published: 14 October 2005

\begin{abstract}
Unusually large-amplitude morning Pc5 magnetic pulsations during the recovery phase of the huge magnetic storm in November 2003 have been studied by using ground-based multi-point observations. Two main spectral Pc5 enhancements were observed: at $\mathrm{f} \approx 2 \mathrm{mHz}$, which featured slowly increasing frequency with decreasing latitude, and at $\mathrm{f} \approx 3 \mathrm{mHz}$, which was latitude independent. The Pc5 pulsations were observed at wide range of latitudes (more than $10^{\circ}$ ) with the same very strong amplitude (up to $500 \mathrm{nT}$ ) and with the same polarization. Only the $3-\mathrm{mHz}$ peak was clearly seen in the spectra of pulsating auroral radio absorption, as observed by the Finnish riometer chain. Short and localized bursts of $\mathrm{PiB}(f \sim 50-100 \mathrm{mHz})$ magnetic pulsations and simultaneous short bursts of energetic electron precipitation were observed in the morning sector, as well. The beginning of the large-amplitude morning Pc5 activity occurred simultaneously with a substorm onset in the evening and midnight sectors. However, the spectra of pulsations in the morning and evening sectors were different. They were compared with spectra of IMF and solar wind parameters, measured by ACE spacecraft. The similarity between the spectra of morning Pc5 and IMF $B_{y}$ was found, but the spectra of evening Pi3 pulsations were similar to the spectra of solar wind density variations. The Pc5 and PiB pulsations, as well as bursts of the auroral radio absorption, suddenly disappeared, when the solar wind density abruptly dropped. We suppose that the $\sim 2-\mathrm{mHz}$ Pc5 geomagnetic pulsations could be attributed to field line resonance (FLR), however, the $3-\mathrm{mHz}$ oscillations were apparently non-resonance origin.
\end{abstract}

Keywords. Magnetospheric physics (MHD waves and instabilities; Solar wind-magnetosphere interaction; Storms and substorms)

\section{Introduction}

Several magnetic superstorms occurred in OctoberNovember 2003 (see, e.g. the special issue of Geomagnetism and Aeronomy, Vol. 45, No. 1, 2005). In late October

Correspondence to: N. G. Kleimenova

(kleimen@ifz.ru) there were two huge magnetic storms with $D_{s t}$ as great as $-400 \mathrm{nT}$. The storms were produced by extremely powerful solar flares. When the same active region on the Sun appeared one solar rotation later, a new coronal mass ejection (CME) toward the Earth occurred and as result, a huge geomagnetic storm developed on 20 November 2003 with $D_{s t}=-465 \mathrm{nT}$.

The variations of the $D_{s t}$-index on 20-21 November 2003, as well as the IMF and solar wind data collected from the ACE spacecraft are shown in Fig. 1. The ACE was located far upstream at the distance of $\sim 240 R_{E}$; the estimated time lag for ground observations was about $50 \mathrm{~min}$.

In the main phase of this storm (when the Earth was inside the body of the magnetic cloud), the negative IMF $B_{z}$ was as strong as $-45 \mathrm{nT}$ and IMF B reached $\sim 60 \mathrm{nT}$. During the recovery phase of the storm, on 21 November at $\sim 03: 00$ 06:00 UT, several dense transients were detected by ACE, and at $\sim 06: 00$ UT the solar wind density suddenly dropped to a background level. On the ground a strong substorm was observed at about 05:40 UT, with the AE index more than $1500 \mathrm{nT}$.

During the recovery phase of this storm, unusually strong Pc5 geomagnetic pulsations appeared in the morning sector, when a sharp density enhancement in the solar wind arrived at the dayside magnetopause, at $\sim 03: 00 \mathrm{UT}$. We focus here on the analysis of these magnetic pulsations and pulsating auroral radio wave absorption, as a magnetospheric response to the abrupt density enhancement of solar wind in the recovery phase of a magnetic storm.

\section{Data}

We analysed the magnetic data collected from: (a) the IMAGE network of 21 magnetometer stations $\left(\Phi=54.4-76.1^{\circ}\right.$, unfortunately, there were no data from BJN), (b) the SAMNET magnetometer network at subauroral latitudes and (c) globally distributed INTERMAGNET magnetometer stations (60 stations). We also analyzed data from the Finnish $\sim 30-\mathrm{MHz}$ riometer (a relative ionospheric opacity meter, which detects the presence of energetic particle precipitation) chain at 6 stations, usually completed by magnetometers: 

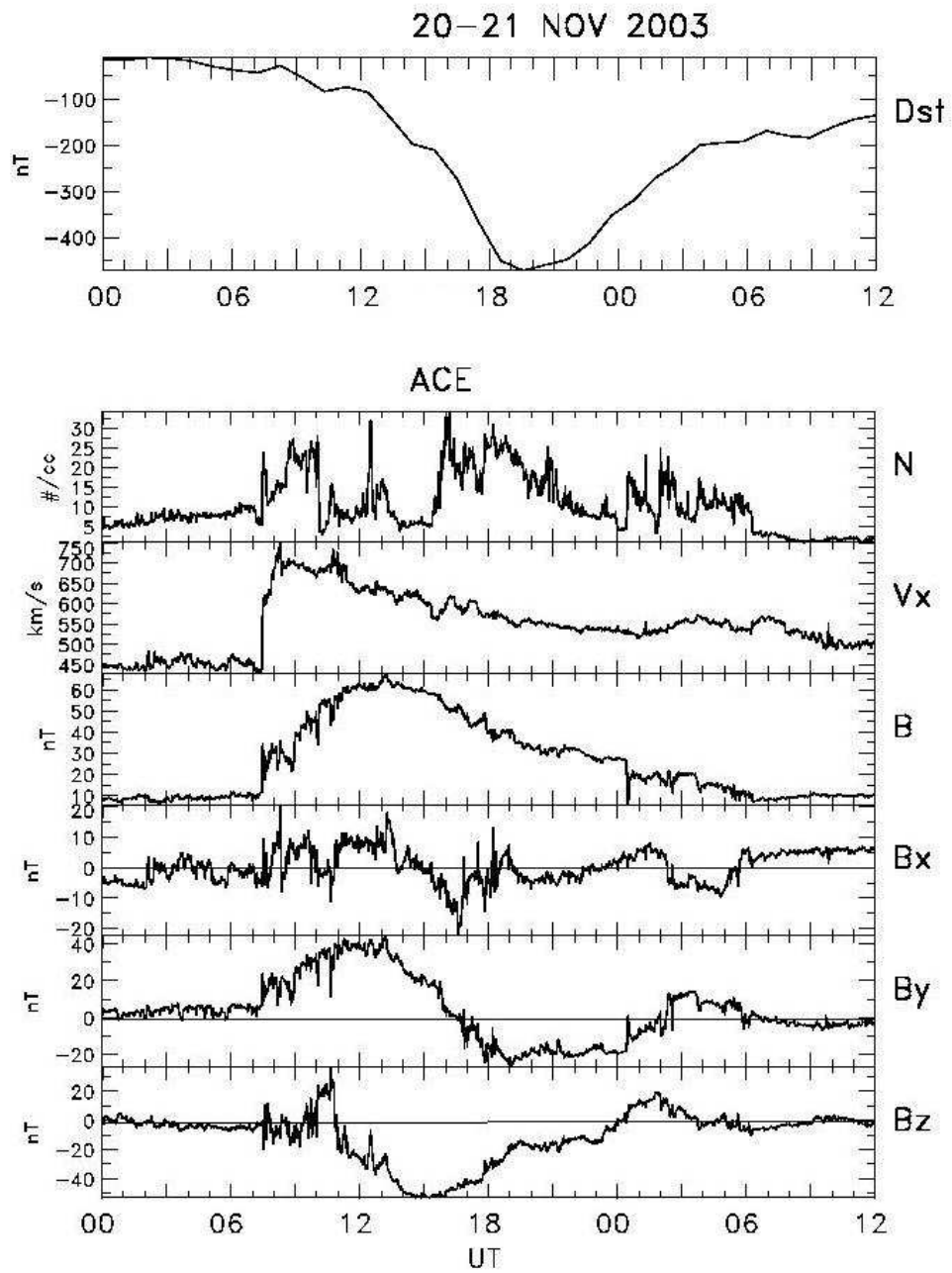

Fig. 1. $D_{s t}$ index and IMF parameters from $\operatorname{ACE}\left(240,22,-15 R_{E}\right)$.

ABK, SOD, IVA, JYV (near IMAGE station HAN), OUL (near IMAGE station OUJ) and ROV (no magnetometer). We have also used here the imaging IRIS $(38.2 \mathrm{MHz})$ riometer at KIL, which has 49 narrow beams. We used the sum of 9 central narrow beams of IRIS to estimate wide beam riometer data. To study short period geomagnetic pulsations $(\mathrm{f}=50-100 \mathrm{mHz}$ ), we used the induction magnetometer data at the Finnish (OUL, ROV, SOD, IVA and KIL) stations. The locations of stations in the IMAGE, SAMNET, Finnish riometer and pulsation magnetometer arrays are shown in the Table 1.

\section{Observations}

3.1 The morning Pc5 magnetic pulsations and auroral absorption

According to IMAGE magnetometer data (Fig. 2) very intense Pc5 magnetic pulsations (peak-to-peak, up to $500-600 \mathrm{nT}$ ) were observed in the morning sector on 21 November. The wave activity suddenly started at $\sim 03: 00$ UT.
Near that time a dense, interplanetary transient (see Fig. 1) reached the magnetosphere. Figure 2 shows that the Pc5 pulsations occurred simultaneously in a wide latitude region $\left(\Phi \approx 55-70^{\circ}\right)$. There was practically no pulsation activity in the polar cap (LYR, NAL), and the pulsation intensity sharply decreased at the latitudes $<55^{\circ}$ (TAR). The pulsation activity suddenly disappeared near 07:30 UT. At that time the sharp density depletion of solar wind reached the Earth's magnetosphere (Fig. 1).

The strongest magnetic pulsations were observed on 21 November, between 05:30 UT and 07:30 UT. The magnetic $\mathrm{X}$ and $\mathrm{Y}$ components (not filtered data) and absorption data are shown in Fig. 3. There were three different bursts of long period pulsations: (1) the first one at 05:45-06:05 UT, (2) the second one at 06:05-06:50 UT, and (3) the third one at 07:00-07:30 UT. The behaviours of the oscillations were different, particularly at 05:40-06:00 UT, when the amplitude of the $\mathrm{Y}$ component strongly increased with latitude while the $\mathrm{X}$ component was practically latitude independent. After 06:00 UT the $X$ component became twice stronger than the Y component, and increased with latitude while the 
Table 1. The parameters of the IMAGE, SAMNET, Finnish riometer and pulsation magnetometers.

\begin{tabular}{|c|c|c|c|c|c|}
\hline $\begin{array}{l}\text { Satellite } \\
A C E\end{array}$ & & $\begin{array}{c}x \\
240\end{array}$ & $\begin{array}{c}\mathbf{Y} \\
22\end{array}$ & $\begin{array}{c}\mathbf{Z} \\
-15\end{array}$ & \\
\hline abbrev & name & geogr. lat & geogr. long & CGM lat & CGM long \\
\hline NAL & Ny Ålesund & 78.79 & 11.95 & 76.07 & 112.25 \\
\hline LYR & Longyearbyen & 78.20 & 15.82 & 75.12 & 113.00 \\
\hline SOR & Sørøya & 70.54 & 22.22 & 67.24 & 106.71 \\
\hline TRO & Tromsø & 69.66 & 18.94 & 66.54 & 103.44 \\
\hline AND & Andenes & 69.30 & 16.03 & 66.36 & 100.92 \\
\hline MAS & Masi & 69.46 & 23.70 & 66.07 & 106.92 \\
\hline KIL & Kilpisjärvi & 69.02 & 20.79 & 65.78 & 104.31 \\
\hline LEK & Leknes & 68.13 & 13.54 & 65.35 & 98.31 \\
\hline ABK & Abisko & 68.35 & 18.82 & 65.04 & 103.31 \\
\hline IVA & Ivalo & 68.56 & 27.29 & 64.75 & 110.06 \\
\hline MUO & Muonio & 68.02 & 23.53 & 64.62 & 105.70 \\
\hline LOZ & Lovozero & 67.97 & 35.08 & 64.10 & 114.89 \\
\hline SOD & Sodankylä & 67.37 & 26.63 & 63.80 & 107.70 \\
\hline PEL & Pello & 66.90 & 24.08 & 63.46 & 105.38 \\
\hline RVK & Rørvik & 64.94 & 10.98 & 62.20 & 93.80 \\
\hline OUJ & Oulujärvi & 64.52 & 27.23 & 60.89 & 106.54 \\
\hline $\mathrm{DOB}$ & Dombås & 62.07 & 09.11 & 59.31 & 90.83 \\
\hline HAN & Hankasalmi & 62.30 & 26.65 & 58.62 & 104.99 \\
\hline UPS & Uppsala & 59.90 & 17.35 & 56.81 & 102.54 \\
\hline NUR & Nurmijärvi & 60.50 & 24.65 & 56.83 & 103.04 \\
\hline TAR & Tartu & 58.26 & 26.46 & 54.37 & 103.32 \\
\hline ROV & Rovaniemi & 66.78 & 25.94 & 62.90 & 107.00 \\
\hline OUL & Oulu & 65.08 & 25.90 & 61.50 & 106.00 \\
\hline JYV & Jyväskylä & 62.42 & 25.28 & 58.50 & 104.20 \\
\hline IRIS & Kilpisjärvi & 69.05 & 20.79 & 65.78 & 104.31 \\
\hline BRW & Barrow & 71.40 & 203.70 & 69.71 & 250.08 \\
\hline FCC & Fort Churchill & 58.80 & 265.90 & 69.80 & 329.00 \\
\hline BLC & Baker Lake & 64.30 & 264.00 & 74.18 & 326.45 \\
\hline GDH & Godhavn & 69.25 & 306.47 & 77.29 & 41.40 \\
\hline HRN & Hornsund & 77.00 & 15.60 & 74.03 & 110.84 \\
\hline
\end{tabular}

Y component showed a maximum near $64-65^{\circ}$ (SOD-IVA). In the third Pc5 burst (07:00-07:30 UT) the amplitude of the $\mathrm{X}$ and $\mathrm{Y}$ components became approximately the same. Also, at the same time a strong decrease in electron precipitation (riometer absorption) was observed at all latitudes (Fig. 3, bottom panel).

The second Pc5 magnetic pulsation burst was accompanied by a simultaneous enhancement of pulsating absorption from OUL to ABK, where the strongest value $4 \mathrm{~dB}$ was observed at ROV (Fig. 3, bottom panel).

\subsection{The spectral analysis}

The Fourier amplitude spectra of magnetometer and riometer data are shown in Fig. 4 for two time intervals: 05:4506:45 UT and 07:00-07:30 UT. In the first interval there were two main enhancements in the spectra of magnetic pulsation: the first at $2 \mathrm{mHz}$ and the second at $3 \mathrm{mHz}$. The lower $(2 \mathrm{mHz})$ maximum was observed only at highlatitude stations (SOD-SOR), with the maximum amplitude at $\Phi=64-65^{\circ}$ and with the peak frequency increasing slowly from $1.9 \mathrm{mHz}$ at SOR to $2.1 \mathrm{mHz}$ at SOD. The higher frequency $(2.8-2.9 \mathrm{mHz})$ enhancement was seen in a large latitude area $\left(\Phi \approx 58-67^{\circ}\right)$. The maximum occurred at OUJ.

The spectra of pulsations of the auroral radio absorption (Fig. $4 \mathrm{a}$, in the middle) were more complicated. No strong enhancements were observed at $\sim 2 \mathrm{mHz}$. One common maximum was observed at $1.4-1.6 \mathrm{mHz}$. The frequency of the second maximum increased from $2.5-2.6 \mathrm{mHz}$ at SOD-IVA to $2.7-2.9 \mathrm{mHz}$ at ROV-OUL. We have compared these spectra with the spectra of magnetic Pc5 pulsations at SOD and OUL (Fig. 4b). The spectra of magnetic pulsations (red line) and oscillations in precipitation (blue line) at OUL were relative similar (except the $1.4-1.6 \mathrm{mHz}$ peak in absorption) and showed a common main peak at $\sim 3 \mathrm{mHz}$. However, at SOD the main peak in the spectrum of magnetic pulsation at $\sim 2 \mathrm{mHz}$ was not accompanied by a significant enhancement in precipitation.

The spectra of magnetic pulsations at 07:00-07:30 UT (Fig. 4a, right panel) reveal that these pulsations were rather monochromatic, with one maximum shifted from $1.6 \mathrm{mHz}$ at SOR to $1.9 \mathrm{mHz}$ at HAN. The maximum amplitude occurred at $\Phi \approx 64-65^{\circ}$ (SOD-ABK) likewise, as in the previous time interval. These magnetic pulsations were accompanied by a strong decrease in the auroral radio absorption (Fig. 3).

The dynamic spectra of the Pc5 pulsations in the morning sector (Fig. 5) show that the pulsations started first at higher frequencies $(2.7-3.2 \mathrm{mHz})$. The waves occurred simultaneously in a wide range of geomagnetic latitudes $\left(58-65^{\circ}\right)$ with maximum amplitude at OUJ. About 15 min later the maximum intensity of pulsations shifted into lower frequencies $(1.7-2.3 \mathrm{mHz})$. The burst of pulsations with similar amplitude and duration was observed from SOD to ABK.

The phase delay of the $3-\mathrm{mHz}$ pulsations was about $60-70 \mathrm{~s}$ between OUJ and $\operatorname{SOD}\left(\Delta \Phi=2.8^{\circ}\right)$, and about 


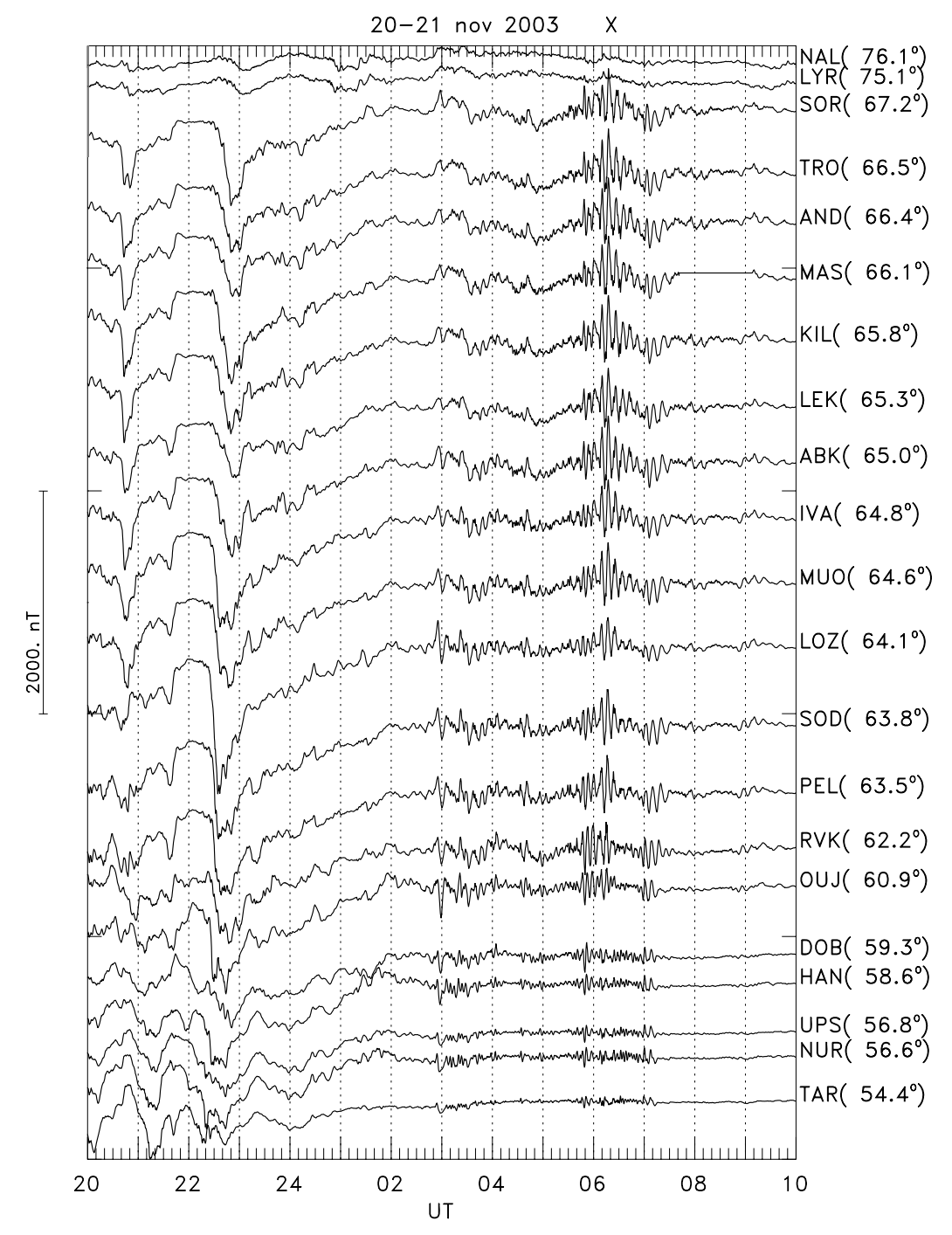

Fig. 2. IMAGE magnetometer data (X component) during the recovery phase of the magnetic storm on 20-21 November 2003. The codes of the stations and their corrected geomagnetic latitudes indicated are on the right side.

90-100 s between SOD and SOR $\left(\Delta \Phi=3.4^{\circ}\right)$. Waves propagated from OUJ to the higher latitudes, with an apparent horizontal speed of $3.5-4.0 \mathrm{~km} / \mathrm{s}$. As a result, the $3-\mathrm{mHz}$ pulsations at SOR became approximately anti-phase with pulsations at OUJ. However, there were no phase delays between the stations at lower latitudes (HAN, NUR, UPS). At these stations the waves were approximately in phase. The 2-mHz magnetic pulsations also propagated from lower (SOD) to higher latitudes with the similar phase speed. The azimuthal wave number $(m)$ estimated by comparing data from the easternmost $\left(\mathrm{LOZ}, \Lambda=114.9^{\circ}\right)$ and the westernmost (LEK, $\Lambda=98.3^{\circ}$ ) IMAGE stations was about 2 for both frequencies.

The rotation of the polarization vector of $1.7-2.3 \mathrm{mHz}$ waves, as well as $2.7-3.2 \mathrm{mHz}$ waves, were counterclockwise at all stations where the Pc5 wave was observed. The polarization reversal was observed across the equatorial boundary (HAN) of this area.
3.3 The PiB magnetic pulsations and auroral absorption

We have also analyzed the data collected from the induction magnetometers at six Finnish stations (NUR, OUL, ROV, SOD, IVA and KIL). The dynamic power spectra (in arbitrary units) of these shorter period magnetic pulsations ( $\mathrm{f}=50$ $100 \mathrm{mHz}$ ) are presented in Fig. 6. The top panel in Fig. 6 shows the unfiltered magnetic Pc5 pulsations at SOD. The absorption data at a given station is shown by a solid black line. Because of the lack of wide beam riometer data at KIL, we used as wide beam values a sum of 9 central narrow beams from IRIS.

The strongest magnetic Pi pulsations were observed at the frequencies less than $70-80 \mathrm{mHz}$. The pulsations looked like short bursts and they can be attributed to PiB type (Heacock, 1967). The PiB pulsations at all stations except SOD suddenly disappeared from 06:00-06:15 UT. There was no precipitation before 05:55 UT, when strong $\mathrm{PiB}$ pulsations 


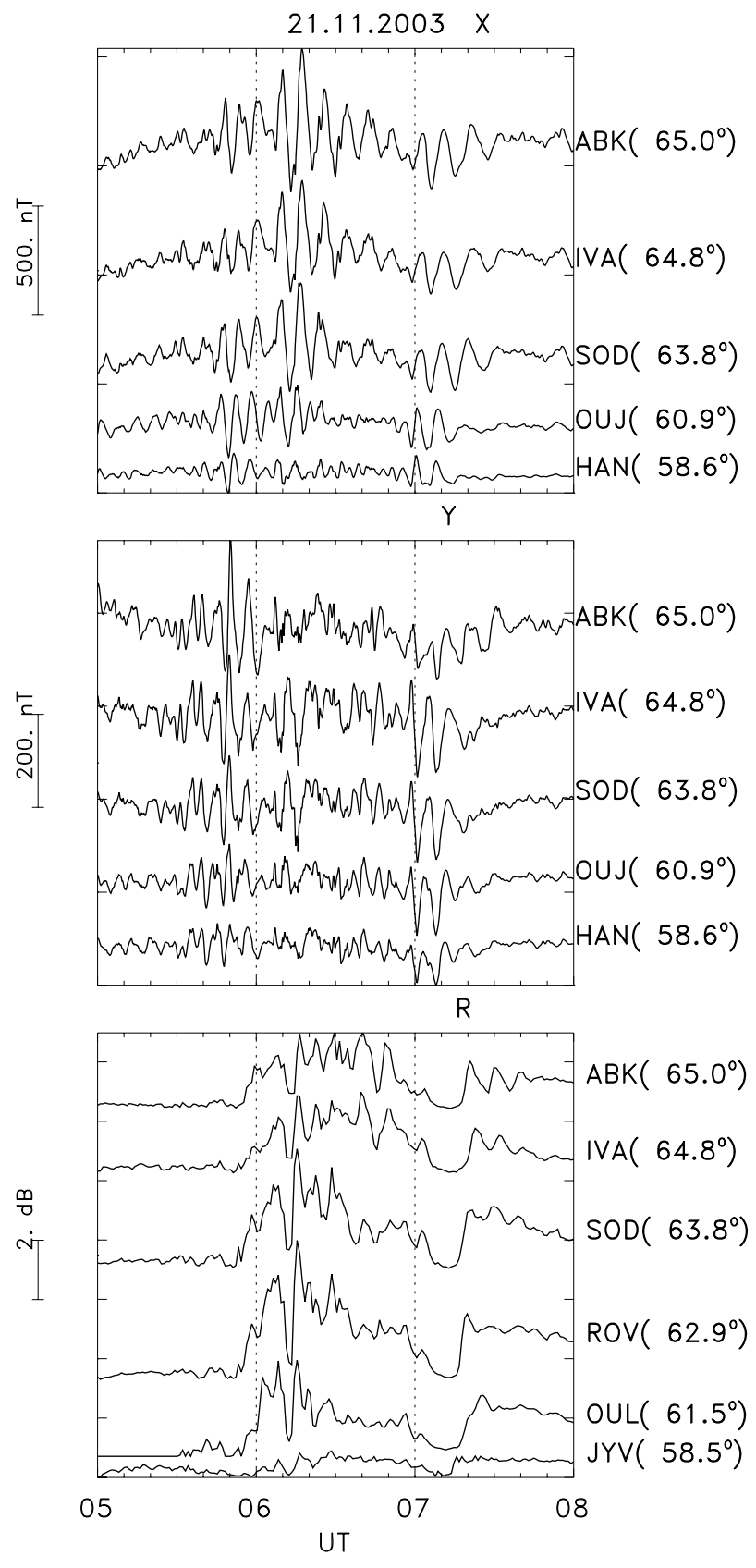

Fig. 3. The $X$ and $Y$ components of magnetic field variations and riometer data (bottom) at the selected Finnish stations in the time interval 04:00-08:00 UT on 21 November 2003.

were observed. However, at 05:55-06:15 UT an enhancement in precipitation was observed at all stations. After 06:00 UT practically each burst of PiB pulsations had a oneto-one correspondence to the absorption peaks. The best correlation between the $\mathrm{PiB}$ and precipitation was observed at SOD, where the strongest PiB pulsations occurred. The PiB pulsations at all stations, as well as the bursts of auroral radio absorption, suddenly decreased at about 07:00 UT, when the solar wind density abruptly dropped.
To examine the dynamics of the regions of the auroral absorption, we used data from the IRIS imaging riometer located at KIL (geographic latitude $69^{\circ}$ ). Details of the imaging riometer and of the data processing technique are given by Detrick and Rosenberg (1990). The field-of-view of this instrument is about $250 \times 250 \mathrm{~km}$ at $90 \mathrm{~km}$ altitude. The absorption keogram (geographic latitude - UT), shown in Fig. 7, and the bottom panel of Fig. 3, indicate that the absorption before $\sim 06: 00$ UT was not as intense as it was afterward. Five well-defined absorption bursts, marked in Fig. 7 by a red number, were compared with $\mathrm{PiB}$ dynamic spectra in Fig. 6. Each of them (vertical arrows with numbers in Fig. 6) has a one-to-one correspondence to PiB bursts at KIL and the peaks in riometer data. The first precipitation burst (at 06:07-06:09 UT) and the second (at 06:16-06:17 UT) occurred south of KIL, as well as the most intense PiB pulsations. The strongest absorption burst, observed at 06:40 06:43 UT, also started south of KIL and shifted very quickly to the zenith. We may conclude that the bursts of PiB magnetic pulsations show similar spatial and temporal dynamics as the bursts of particle precipitations.

\subsection{The morning Pc5 pulsations and night side substorm}

The AE index (not shown here) indicates that a short, strong substorm (AL $=-1400 \mathrm{nT}$ and $\mathrm{AU}=200 \mathrm{nT})$ suddenly started at 05:40 UT. The magnetic data in Fig. 8 from BRW, which was located in the evening sector (18:00-20:00 MLT), and FCC and BLC, which were located near local midnight (22:00-24:00 UT), also confirm the substorm development. The second substorm activation started a half an hour later (at 06:05 UT), near midnight (BLC). There was no significant activity at polar latitudes in Greenland (GDH) and Svalbard (HRN). The SOD data in Fig. 8 shows Pc5 pulsations in the morning sector. One can see that the bursts of the Pc5 pulsations in the morning sector started simultaneously with substorm activations in the evening side. The obtained results confirm the earlier studies by Afanasyeva (1978) and Rostoker et al. (1984), who found that morning Pc5 magnetic pulsation activity increases with a substorm onset in the night sector.

The spectra of simultaneous morning Pc5 and evening Pi3 magnetic pulsations were different (Fig. 9), as it was previously found by Pilipenko et al. (1997). The main peaks at $2 \mathrm{mHz}$ and $3 \mathrm{mHz}$ observed in the spectra of the morning Pc5 magnetic pulsations (SOD, OUJ, Fig. 9, left panel) coincided with the clearly defined minima in the spectra of evening Pi3 magnetic pulsations (BRW, CMO, Fig. 9, right panel).

3.5 The comparison of the spectra of morning and evening magnetic pulsations with the spectra of IMF and solar wind density

We also compared the spectra of magnetic pulsations in the morning and evening sectors with the corresponding oscillations in IMF and solar wind density (Fig. 9). We found that only the spectrum of IMF $B_{y}$ in the far upstream solar 

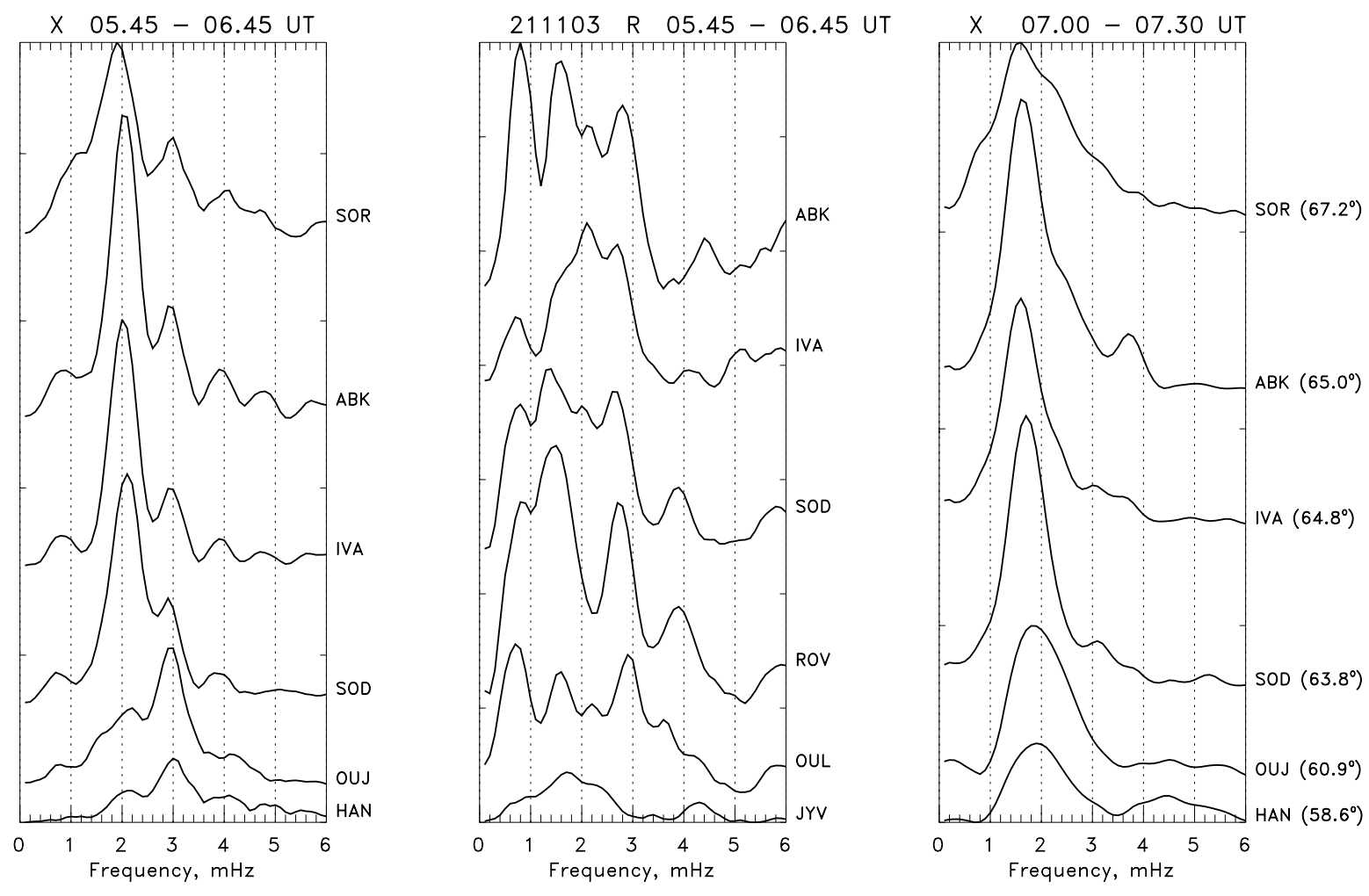

(a)
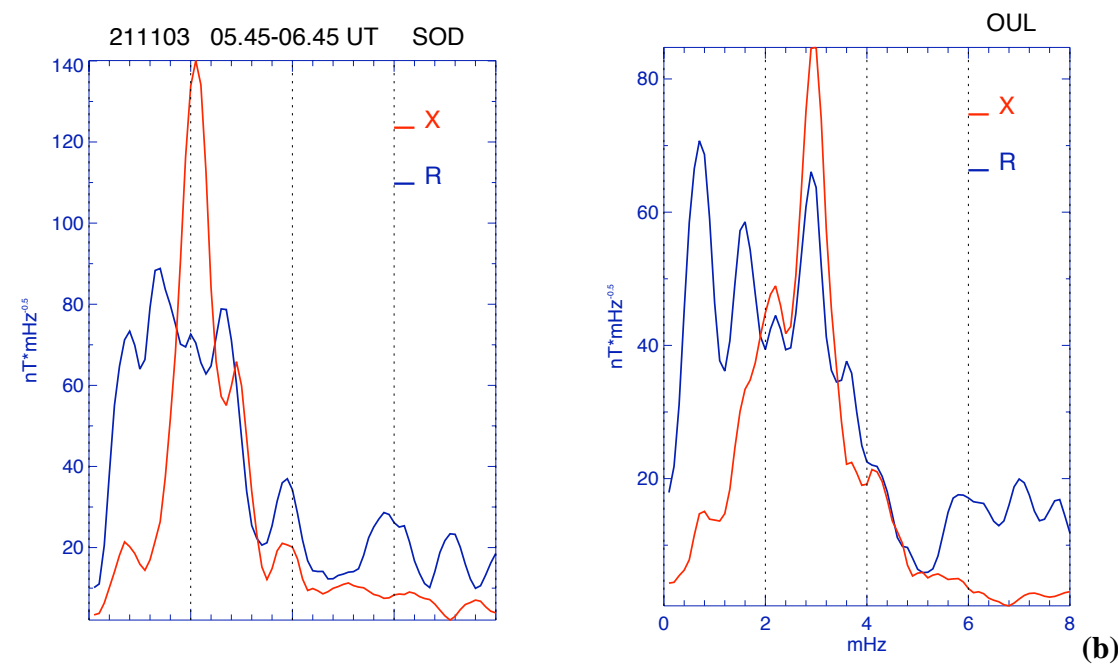

Fig. 4. (a) Fourier spectra of the $X$ component of magnetic field variations and radio absorption (arbitrary units) at stations shown in Fig. 3 for the time intervals 05:45-06:45 UT and spectra of the X component in 07:00-07:30 UT; (b) comparison the spectra of Pc5 magnetic (red line) and absorption (blue line) pulsations at OUL and SOD.

wind (ACE spacecraft, $\mathrm{X}=240 R_{E}$ matched with the spectra of the morning Pc5 pulsations and showed enhancements at $\sim 2 \mathrm{mHz}$ and $\sim 3 \mathrm{mHz}$ (Fig. 9, left panel). However, the main maximum $(\sim 2.4-2.5 \mathrm{mHz})$ in the spectra of density variations of solar wind fits with the maximum in the spectra of the evening pulsations (Fig. 9, right panel). This indicates that the nightside magnetosphere is remarkably sensitive to density oscillations of solar wind.

\subsection{Global distribution of Pc5 magnetic activity}

The distribution of global pulsation activity ( $\Phi$-MLT plots) was computed for three time intervals, 05:30-06:00 UT, 06:00-06:30 UT and 07:00-07:30 UT, based on magnetic data from 64 ground stations, Fig. 10. The frequency band corresponds to the main enhancement in the wave spectra in the given time interval shown in Fig. 5. 


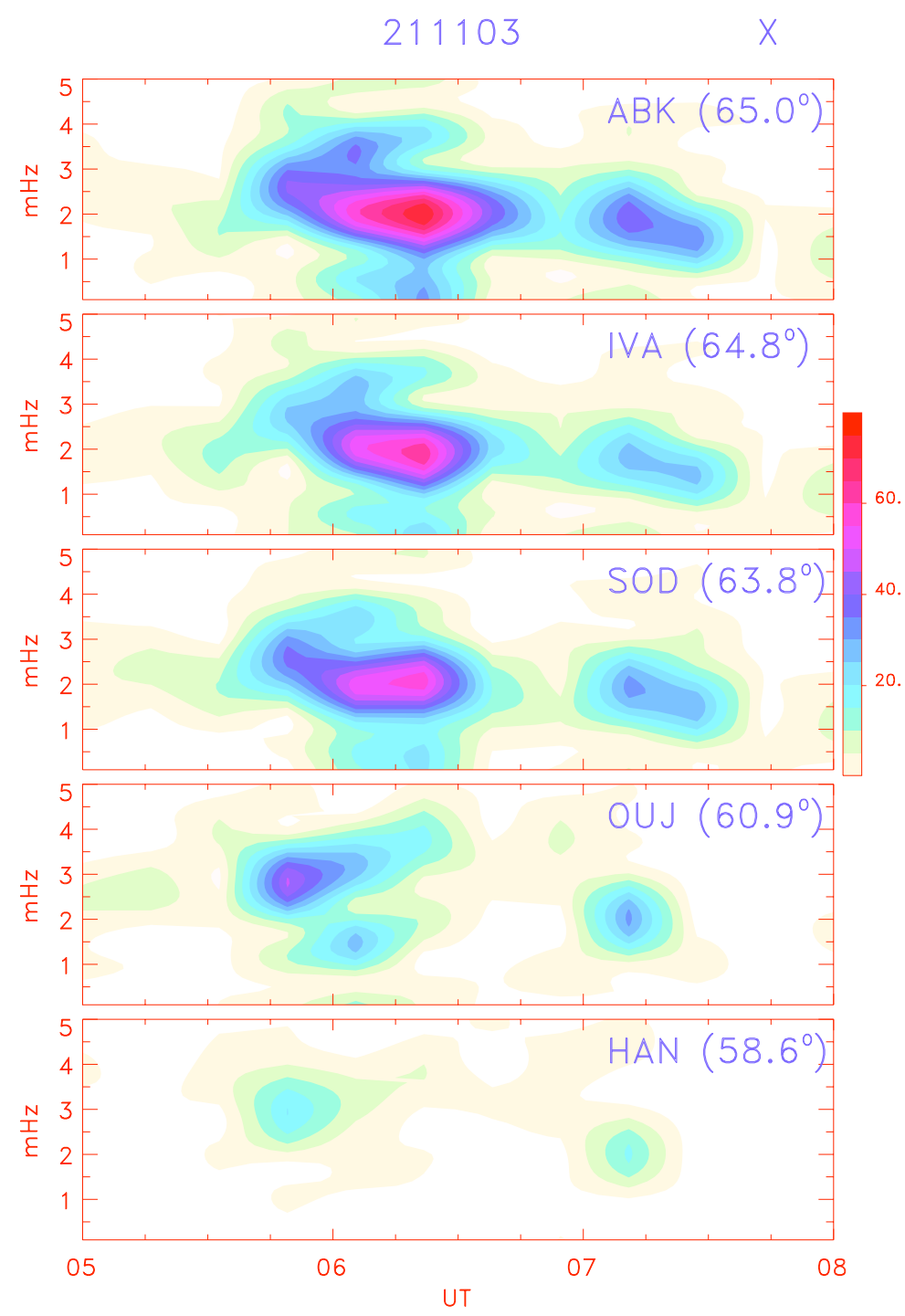

Fig. 5. Dynamic amplitude spectra of Pc5 pulsations (nT/mHz $\left.{ }^{0.5}\right)$ observed at selected IMAGE stations.

The strongest pulsations are seen in the morning sector. In the first time interval the main intensity of the $2.7-3.2 \mathrm{mHz}$ pulsations (Fig. 10, upper panel) was concentrated in a considerably narrow latitude range $\left(\Phi \approx 61-63^{\circ}\right)$. But the strong 1.7-2.3-mHz pulsations in the second time interval (Fig. 10, middle panel) appeared in a much wider area $\left(\Phi \approx 60-70^{\circ}\right)$. The maps indicate a sharp equatorial boundary shifting to higher latitudes, from HAN $\left(\Phi \approx 58^{\circ}\right)$ to OUJ $\left(\Phi \approx 61^{\circ}\right)$. The morning pulsations in the two first intervals were accompanied by magnetic pulsation activity at auroral latitudes in the evening sector. The strong decrease of Pc5 pulsations intensity at the midnight sector (Fig. 10) is consistent with the results obtained by Hudson et al. (2004). They concluded that this was due to a clear absence of fundamental toroidal mode power near midnight. In the third interval (Fig. 10, bottom panel) strong nighttime pulsations were observed near midnight and only at the geomagnetic latitude at around $70^{\circ}$; the evening sector was relatively undisturbed.

\subsection{The summary of the observed results}

The observed features of magnetic Pc5 pulsations in the morning sector in the recovery phase of the November 2003 superstorm can be summarized as follows: (1) their amplitudes were unusually strong, several times stronger than typical values; (2) they occurred at unusually large latitude area (more than $10^{\circ}$ ) with the same strong amplitude and polarization; (3) the sense of polarization reversed across a sharp low-latitude boundary of Pc5 occurrence; (4) the spectral peak frequency at $3 \mathrm{mHz}$ did not change with latitude, however, the spectral peak frequency at $2 \mathrm{mHz}$ slowly increased with decreasing latitude; (5) only the second Pc5 burst was accompanied by a pulsating enhancement in auroral radio absorption, with a common spectral maximum near $3 \mathrm{mHz}$; (6) Pc5 pulsation activity started suddenly, simultaneously with an impulsive enhancement of solar wind density and the wave disappeared when a sharp density depletion of 

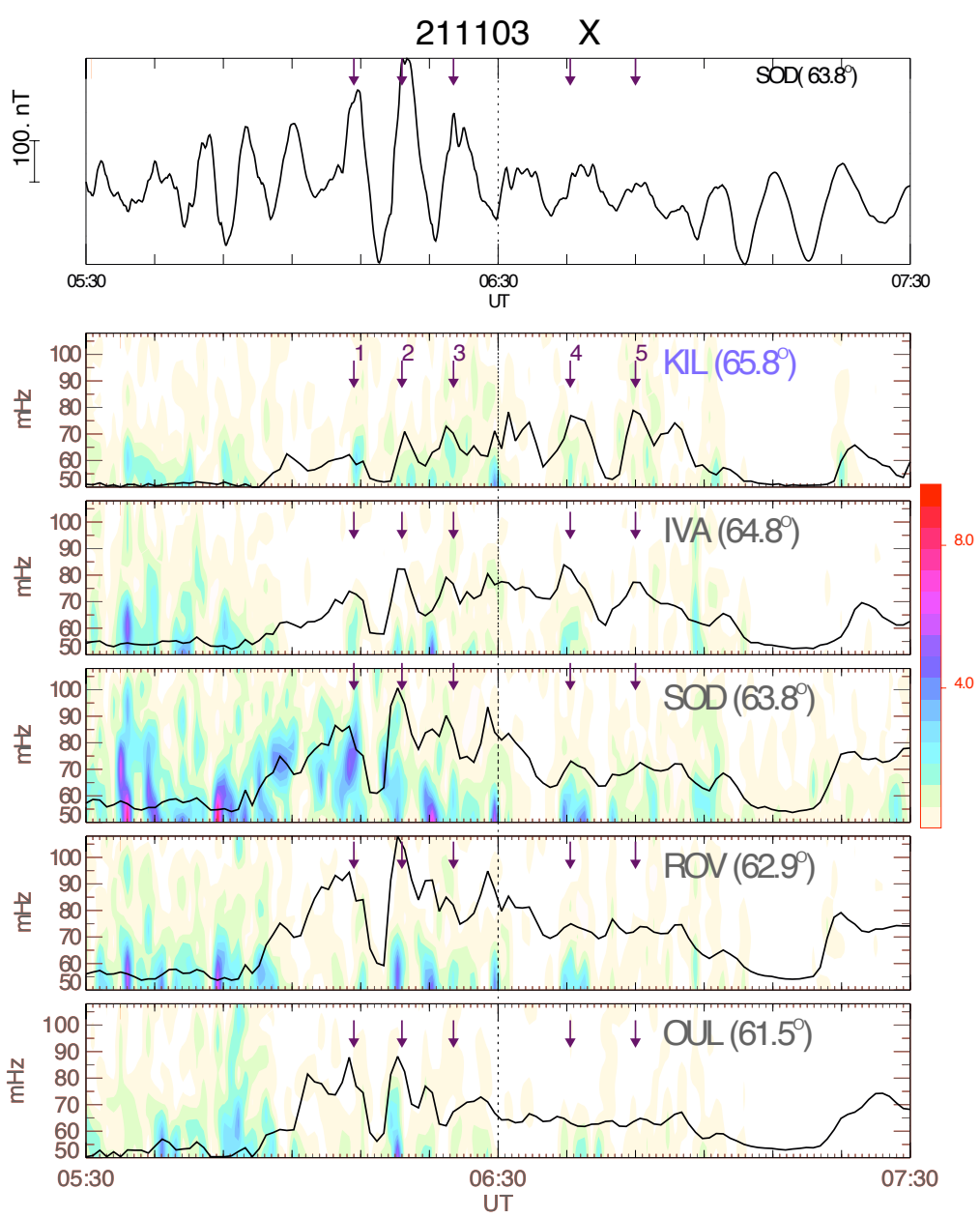

Fig. 6. The dynamic power spectra of Pi1 type short period ( $\mathrm{f}=50-100 \mathrm{mHz}$ ) magnetic pulsations (in arbitrary units), collected from five Finnish stations, in comparison with riometer data (black lines) and Pc5 pulsations. The arrows with numbers indicate that the short bursts of Pi1 coincided with the absorption peaks (see Fig. 7).

solar wind reached the Earth's magnetosphere; (7) the spectra of Pc5 pulsations in the morning sector did not fit with the spectra of the solar wind density variations but showed some similarity with spectra of IMF $B_{y}$; however, the spectra of evening-midnight side pulsations showed some similarity with the spectra of solar wind density; (8) the strongest Pc5 bursts in the morning sector started simultaneously with substorm activations in the evening side, but the spectra of pulsations in the morning and evening sectors were different.

\section{Discussion}

Numerous ground and satellite observations (e.g. Oberts and Raspopov, 1968; Gupta, 1975; Ziesolleck and McDiarmid, 1995; Engebretson et al., 1998; Nosé et al., 1998; Baker et al., 2003; Posch et al., 2003 and many others) show that classical Pc5 magnetic pulsations typically have a peak occurrence at the dawn sector of the magnetosphere. Usually, these waves are attributed to a toroidal wave of fundamental mode of field line resonance (FLR), which dominates on the dawn side. There are two principally different ways for coupling the solar wind energy into Pc5 range pulsations observed on the ground: (1) the fast solar wind streams lead to an enhanced Kelvin-Helmholtz instability on the flanks of the magnetosphere, mainly on the dawn flank and that arouses enhanced ULF waves inside the magnetosphere through surface mode (e.g. Miura, 1992) or by cavity/waveguide modes (e.g. Samson et al., 1992; Mann et al., 1999); (2) fluctuations in the solar wind can directly drive ULF waves in the magnetosphere (Kepko et al., 2002; Stephenson and Walker, 2002) or lead to an enhanced excitation of the field line resonance or cavity/waveguide magnetospheric waves.

The strong morning Pc5 pulsations discussed in this paper can be attributed to FLR exited by high solar wind speed $(\sim 550 \mathrm{~km} / \mathrm{s})$. However, the observed maxima at $\sim 2 \mathrm{mHz}$ and $\sim 3 \mathrm{mHz}$ in the spectra of ULF waves do not fit with the known multiple, discrete FLR frequencies of 1.3, 1.9, 2.6 and $3.4 \mathrm{mHz}$ (e.g. Samson et al., 1992). Only the 2$\mathrm{mHz}$ peak may be clearly attributed to a $1.9-\mathrm{mHz}$ FLR peak. Moreover, the frequency of the 2-mHz peak slowly increased 
21 NOV 2003

IRIS absorption keogram

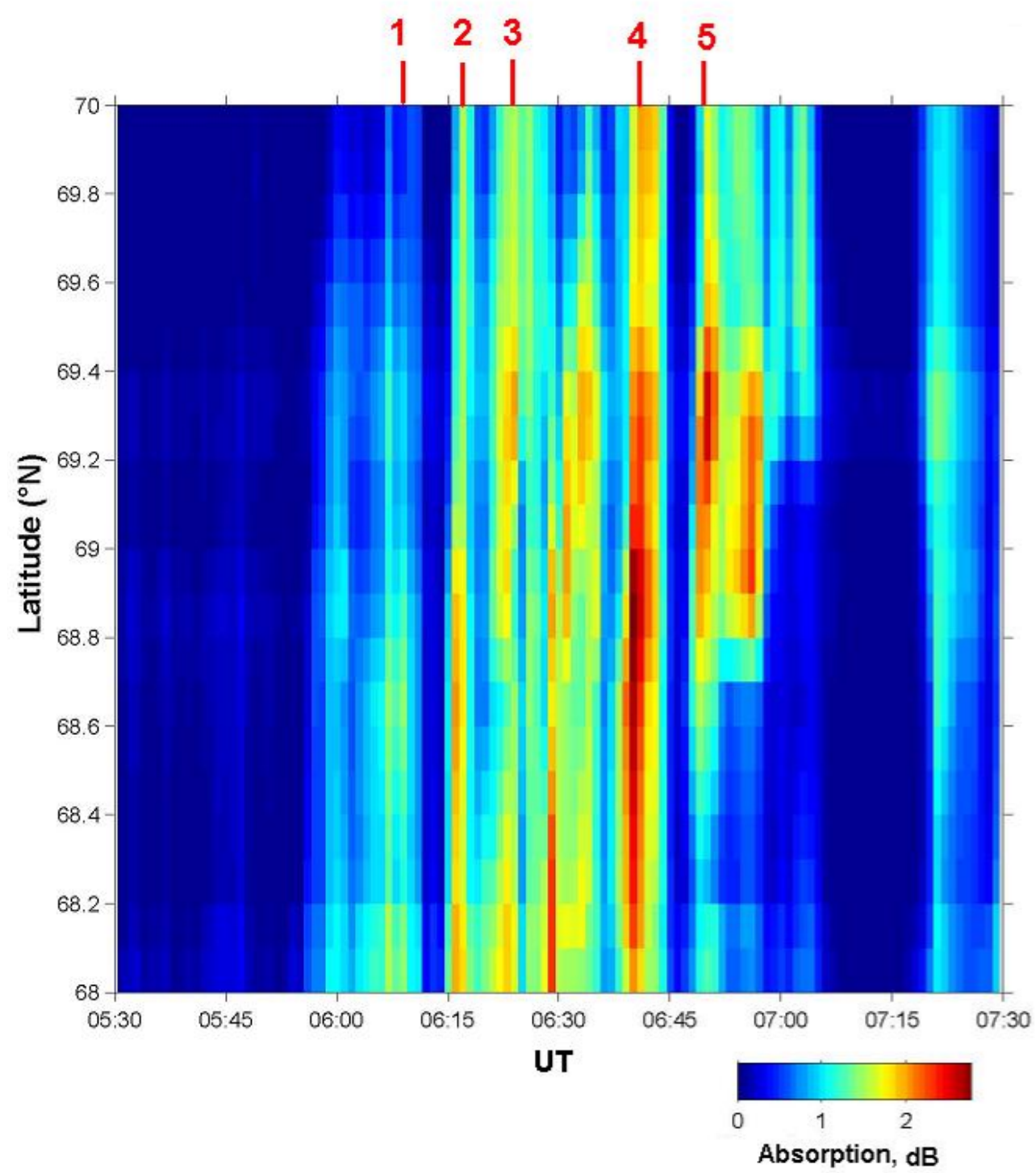

Fig. 7. IRIS absorption keogram (05:30-07:30 UT) in geographic coordinates; the red numbers show the strong electron precipitation bursts.

with decreasing latitude, while the $3-\mathrm{mHz}$ peak was latitude independent. The similar strong daytime Pc5 pulsations with latitude independent frequency maximum near $3 \mathrm{mHz}$ were observed at a wide latitude region in the recovery phase of another huge magnetic storm on 31 October 2003 (Kleimenova and Kozyreva, 2005).

The very strong burst of $2-\mathrm{mHz}$ pulsations observed at 06:05-06:40 UT (Fig. 3) was most pronounced in the X component, which was much larger than the Y component. This fits with the FLR criteria. On the contrary, the X-component of the 3-mHz pulsations (05:40-06:05 UT) was of the same order or less than the $\mathrm{Y}$ component, which increased with increasing latitude.

One of the main properties of FLR, observed on the ground, is a rapid phase variation across the latitude, corresponding to a resonant L-shell (maximum of the $\mathrm{X}$ component amplitude) and a reversal of the sense of polarization. But this was not observed in the discussed event. At all IMAGE stations from OUJ to SOR, where strong Pc5 pulsations were observed, the polarization of the waves both at $\sim 2 \mathrm{mHz}$ and at $\sim 3 \mathrm{mHz}$, was counterclockwise.

Radar (Walker et al., 1992) and satellite (e.g. Mitchell et al., 1990) observations have shown that equatorial resonance width of FLR can be as small as $0.5 R_{E}$. Glassmeier and Stellmacher (2000) estimated that the radial resonant width is between $0.1 R_{E}$ and $0.28 R_{E}$ in the equatorial plane of the magnetosphere or on the order of $50-150 \mathrm{~km}$ at the ionospheric level. The wave transmission through the ionosphere and atmosphere to the ground provides some modifications of the FLR structure. The main effect consists 


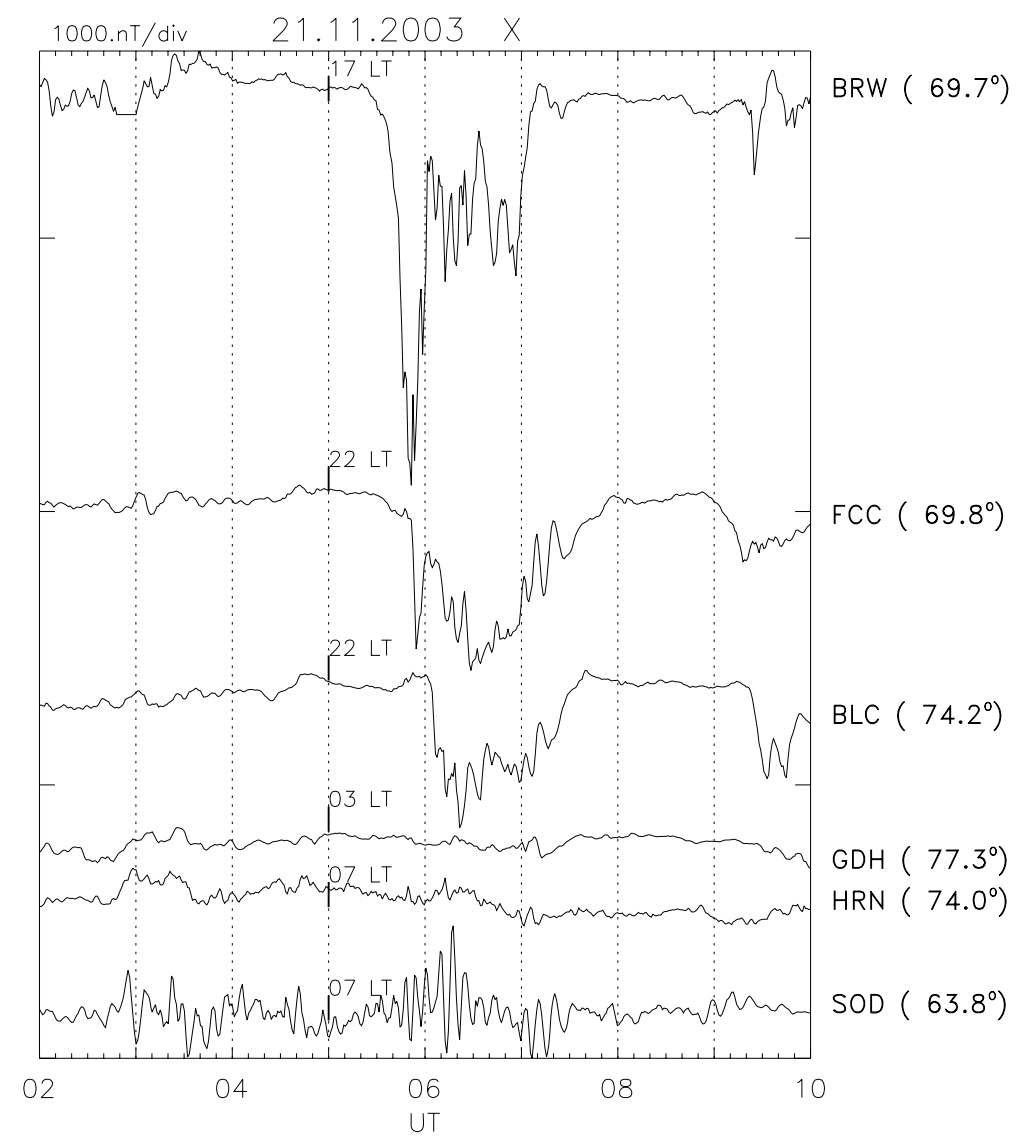

Fig. 8. The comparison of the morning Pc5 pulsation (SOD) occurrence with the substorm activity in the evening (BRW, FCC, and BLC) and morning polar cap (HRN, GDH) magnetic data.

of a smoothing of the amplitude and phase variations through the resonant region (Poulter and Allan, 1985). The large latitudinal dimension of the respective FLR signal observed on the ground with the amplitudes above half of the maximum can reach about $400 \mathrm{~km}$ (see Fig. 3 by Glassmeier and Stellmacher, 2000). In the considered event on 21 November 2003 the area of the equally strong amplitude of Pc5 with the same polarization was three times of that as large .

- Thus, it is difficult to explain the observed Pc5 pulsations in terms of FLR.

In the morning sector we observed the strong Pc5 pulsations at lower latitudes (L-values 4-6) than they typically occur, at $\mathrm{L} \approx 6-8$ (e.g. Glassmeier and Stellmacher, 2000; Hudson et al., 2004). This could be a result of their occurrence during the recovery phase of a huge magnetic storm, when the magnetosphere was considerably compressed, and the Pc5 source was located at lower L shells than under ordinary conditions. During this time the auroral oval might be greatly expanded, and according to Rostoker and Lam (1978) and Lam and Rostoker (1978), the source of Pc5 activity is co-located with the auroral oval.
A sudden change in the solar wind dynamic pressure may produce a mechanism for the excitation of cavity mode waves in the magnetosphere (e.g. Allan et al., 1986; Lee and Lysak, 1989). Standing Alfvén wave frequencies (FLR) matching that of the cavity mode eigenfrequencies may be excited (Goldstein et al., 1999). A similar result was published recently by Hudson et al. (2004) based on CRRES magnetic field data. Our results confirm that the dynamic pressure enhancement in solar wind may lead to Pc5 excitation in the dayside magnetosphere.

The Pc5 activity, as well as auroral radio absorption, disappeared at $\sim 07: 00$ UT simultaneously, with the abrupt drop in solar wind density measured by ACE at 06:17 UT. So, when the external driver stopped, the FLR oscillation in the magnetosphere also stopped immediately. However, after 07:00 UT a strong monochromatic Pc5 wave packet (Figs. 24) appeared in the morning side, with the peak frequency increasing from $\sim 1.6 \mathrm{mHz}$ to $\sim 1.9 \mathrm{mHz}$ and with the same counter-clockwise polarization. The Pc5 burst was accompanied by a decrease in particle precipitation, as observed by riometers. The source of these Pc5 pulsations is still unknown.

We confirm the previous studies (Afanasyeva, 1978; Rostoker et al., 1984), which showed that the morning Pc5 
magnetic pulsation activity increases with a substorm onset in the night sector. We found that each Pc5 wave packet started simultaneously with an onset of a substorm activation in the evening sector. We suppose that a substorm onset and the arising morning Pc5 magnetic pulsations are caused by a common source - a sharp increase in the solar wind dynamic pressure.

According to Lee and Lyons (2004), enhancements in the solar wind dynamic pressure, which occur under northward IMF, generally lead to magnetic compression on the dayside and a depression near local midnight. If it occurred under southward IMF, they still observed magnetic field compression on the dayside, but on the nightside they found a typical magnetic dipolization signature of a substorm.

In the discussed event the morning Pc5 activity suddenly started at $\sim$ 03:00 UT in association with a strong impulsive enhancement in solar wind density at $\sim 02: 10$ UT under positive IMF $B_{z}$ (Fig. 1). No substorm activity was observed on the ground.

After southward turning IMF a strong substorm started at 05:40 UT (simultaneously with sharp morning Pc5 enhancement) and ACE observed several peaks in solar wind density near 05:05 UT. We suppose that the substorm onset and the morning Pc5 pulsation amplification were caused by a common source - an enhancement of solar wind dynamic pressure under southward IMF. The main pulsation activity in the evening and morning sectors began practically simultaneously but with different spectra. Some similarity in the spectra of the evening/night side magnetic pulsations and solar wind density variations suggests that the magnetic waves in the nightside associated with a substorm are remarkably sensitive to variations in the solar wind density.

Several authors (e.g. Kepko et al., 2002; Stephenson and Walker, 2002; Kessel et al., 2004) have found that ground Pc5 magnetic pulsations can be directly driven by pressure variations of solar wind. However, this was not the case in the discussed magnetic storm. In the studied case the morning Pc5 pulsation spectra clearly do not agree in frequency with the solar wind pressure variations (Fig. 9).

- Certainly, the excitation of morning Pc5 pulsations was associated with abrupt enhancements of the solar wind dynamic pressure, but the waves were not directly driven by density oscillations.

A number of observational and theoretical studies have been made on the modulation of particle flux by Pc5 pulsations (e.g. Kokubun et al., 1977; Higuchi et al., 1988; Kleimenova et al., 1997; Nosé et al., 1998). The riometer data on 21 November 2003 showed that only the Pc5 pulsations in the interval of 06:00-07:00 UT were accompanied by pulsating electron precipitation. Coroniti and Kennel (1970) have explained the generation mechanism of pulsations in the energetic electron precipitation through a modulation of the precipitation rate with a wave-particle interaction, which is modulated by compressional ULF waves. This interaction takes place in the equatorial plane of the magnetosphere. In
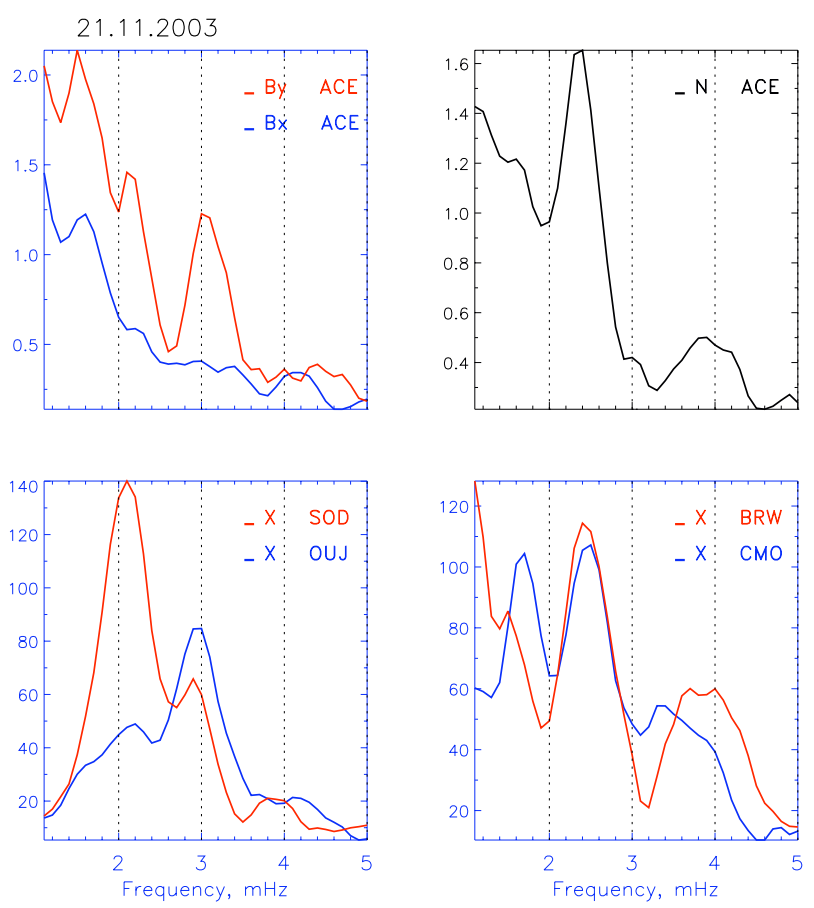

Fig. 9. The comparison of the Fourier spectra of ACE (upper panels) data for 05:45-06:45 UT: $B_{x}$ (blue) and $B_{y}$ (red) of IMF data and solar wind density (black), with the spectra of the ground data (bottom panels): X component of morning Pc5 pulsations at SOD (red) and OUJ (blue), and evening Pi3 pulsations at BRW (red) and CMO (blue).

this case there should be a phase delay between magnetic pulsations and pulsating electron precipitation, due to the difference in travel time of electrons and magnetic waves. Depending on the plasma properties and the L-distance, one would expect this time difference to be of the order of $1 \mathrm{~min}$.

Our analysis shows that the precipitation pulsations (riometer measurements) are leading the magnetic ones for $\sim 40 \mathrm{~s}$ at SOD and IVA. This delay was less in OUL, where the spectra of magnetic and precipitation pulsations were coinciding (Fig. 4b). This fact can be interpreted to imply that the location of the source of the electron precipitation was not far from OUL, probably near $63^{\circ}(\mathrm{ROV})$, where the strongest radio wave absorption was measured (Figs. $3 \mathrm{a}$ and $4 \mathrm{a}$ ).

We compared the phase of the precipitation pulsations at the stations located at different longitudes along similar latitudes $\sim 64-65^{\circ}$ : $\operatorname{ABK}\left(\Lambda=103.0^{\circ}\right)$, SOD $\left(\Lambda=107.7^{\circ}\right)$ and IVA $\left(\Lambda=110.1^{\circ}\right)$, and found that the precipitation pulsations filtered in the frequency band of $2.7-3.2 \mathrm{mHz}$ propagated from SOD, both to the east (IVA) and to the west (ABK).

According to the theory of Coroniti and Kennel (1970), the ULF waves, which are responsible for the modulation of particle precipitation, should have a strong compressional component in the equatorial plane of the magnetosphere. However, in the equatorial plane of the magnetosphere the FLR waves are associated with toroidal azimuthally polarized oscillations, which cannot strongly change the pitch angle of 


\subsubsection{3}
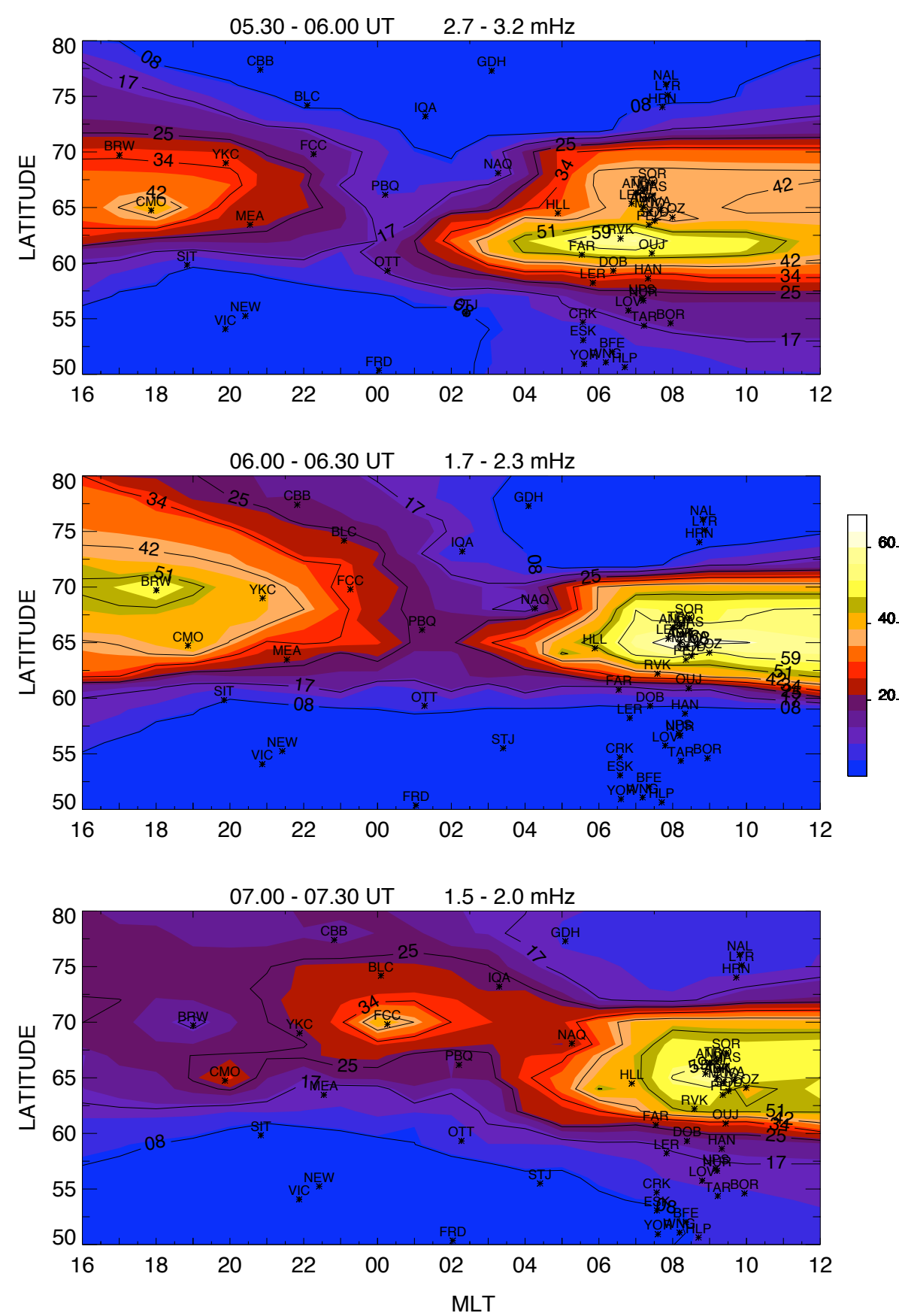

Fig. 10. Distribution maps ( $\Phi$-MLT diagram) of Pc5 magnetic pulsations calculated for three time intervals (indicated on the top of each map) on 21 November 2003 by using the data from 64 ground stations located at the geomagnetic latitudes $\Phi=50-80^{\circ}$.

the trapped particles. In the spectra of pulsating absorption we did not see the typical features of a magnetospheric FLR frequency at $2 \mathrm{mHz}$, but there was a maximum at $3 \mathrm{mHz}$. We suppose that, in particular, the 3-mHz ULF waves, which did not show the FLR properties, had a significant compressional component in the equatorial plane of the magnetosphere. The similar results were obtained earlier by Kleimenova et al. (1997), who found, that in the morning sector at auroral latitudes the pulsations in the magnetic field and in the precipitation were correlated at $\mathrm{f}>2 \mathrm{mHz}$ and non-correlated at $\mathrm{f}<2 \mathrm{mHz}$. We may split the studied morning Pc5 pulsations into two subclasses: FLRs at frequency $2 \mathrm{mHz}$ and non-FLRs at frequency $3 \mathrm{mHz}$. 


\section{Summary}

During the recovery phase of the huge magnetic storm in November 2003, very strong magnetic pulsations in the Pc5 range were observed in the morning sector.

1. Two main spectral maxima were observed: the first at $\mathrm{f} \approx 2 \mathrm{mHz}$, which slowly increased with decreasing latitude and showed some similarity to the FLR properties, and the second at $\mathrm{f} \approx 3 \mathrm{mHz}$, which was latitude independent and could not be attributed to FLR.

2. The observed morning Pc5 pulsations were not directly driven by solar wind pressure oscillations.

3. The beginning of the large-amplitude morning Pc5 activity was accompanied by a substorm onset in the evening/midnight sector and an impulsive enhancement of solar wind dynamic pressure. However, the spectra of simultaneously observed ULF waves in the morning (Pc5) and evening (Pi3) sectors were different. We suppose that they have the common energy source, but different generation mechanisms.

Acknowledgements. The IMAGE magnetometer data used in this paper were collected as part of German-Finnish-Norwegian-Polish cooperation presently headed by the Finnish Meteorological Institute. The authors thank the SAMNET and INTERMAGNET teams for magnetometer data. The authors thank R. Lepping and K. Ogilve at NASA/GSFC and CDAWeb for providing WIND data and D. J. McComas at SWRI and CDAWeb for providing ACE data. The data, originated from the Imaging Riometer for Ionospheric Studies (IRIS), are operated by the Department of Communications Systems at Lancaster University (UK) in collaboration with the Sodankylä Geophysical Observatory, and funded by the Particle Physics and Astronomy Research Council (PPARC). N. Kleimenova and O. Kozyreva thank Sodankyla Geophysical Observatory for the support during their stay at the Observatory.

Topical Editor T. Pulkkinen thanks M. Engebretson and $\mathrm{K}$. Yumoto for their help in evaluating this paper.

\section{References}

Afanasyeva, L. T.: Space-time distribution of geomagnetic pulsations and its dependence on the geomagnetic activity, Acta Geod. Geophys. Mont. Acad. Sci., Hungary, 13(1-2), 239-271, 1978.

Allan, W., White, S. P., and Poulter, E. M.: Impulse-excited hydromagnetic cavity and field-line resonances in the magnetosphere, Planet. Space Sci., 34 (4), 371-378, 1986.

Baker, G. J., Donovan, E. F., and Jackel, B. J.: A comprehensive survey of auroral latitude Pc5 pulsation characteristics, J. Geophys. Res., 108, A101384, doi:10.1029/2002JA009801, 2003.

Coroniti, F.V. and Kennel, C.F.: Electron precipitation pulsations, J. Geophys. Res., 75, 1279-1289, 1970.

Detrick, D. L. and Rosenberg, T. J.: A phased-array radiowave imager for studies of cosmic noise absorption, Radio Sci., 25, 325$338,1990$.

Engebretson, M. J., Glassmeier, K.-H., Stellmacher, M., Hughes W. J., and Lühr, H.: The dependence of high-latitude Pc5 power on solar wind velocity and phase of high-speed solar wind streams, J. Geophys. Res., 103, 26 271-26283, 1998.

Geomagnetism and Aeronomy: special issue, Vol. 45, No. 1, 2005.

Glassmeier, K.-H. and Stellmacher, M.: Concerning the local time asymmetry of Pc-5 wave power at the ground and field line resonance widths, J. Geophys. Res., 105, 18 847-18 855, 2000.

Goldstein, J., Hudson, M. K., and Lotko, W.: Possible evidence of damped cavity mode oscillations stimulated by the January, 1997 magnetic cloud event, Geophys. Res. Lett., 26, 3589-3593, 1999.

Gupta, J. C.: Some characteristics of large amplitude Pc5 pulsations, Austral. J. Phys., 29, 67-87, 1975.

Heacock, R. R.: Two subtypes of Pi micropulsations, J. Geophys. Res., 72, 3905-3917, 1967.

Higuchi, Y., Shibuya, S., and Sato, N.: CNA pulsations accompanying hydromagnetic waves at conjugate stations, Planet. Space Sci., 36, 1255-1267, 1988.

Hudson, M. K., Denton, R. E., Lessard, M. R., Miftakhova, E. G., and Anderson, R. R.: A study of Pc-5 ULF oscillations, Ann. Geophys., 22, 289-302, 2004,

\section{SRef-ID: 1432-0576/ag/2004-22-289.}

Kepko, L., Spence, H. E., and Singer, H. J.: ULF waves in the solar wind as direct drivers of magnetospherc pulsatios, Geophys. Res. Lett., 29, No. 8, doi:10.1029/2001GL014405, 2002.

Kessel, R. L., Mann, I. R., Fung, S. F., Milling, D. K., and $\mathrm{O}^{\prime}$ Connell, N.: Correlation of Pc5 wave power inside the magnetosphere during high speed streams, Ann. Geophys., 22, 629641, 2004,

SRef-ID: 1432-0576/ag/2004-22-629.

Kleimenova, N. G., Kozyreva, O. V., and Ranta, H.: Pc5 pulsations in geomagnetic field and riometers absorption in the morning sector of auroral latitudes, Geomagnetism and Aeronomy (English translation), 37 (5), 552-578, 1997.

Kleimenova, N. G. and Kozyreva, O. V.: Spatial-temporal dynamics of Pi3 and Pc5 geomagnetic pulsations during the extreme magnetic storms in October 2003, Geomagnetism and Aeronomy (English translation), 45, 71-79, 2005.

Kokubun, S., Kivelson, M. G., McPherron, R. I., Russell, C. T., and West Jr., H. I.: Ogo 5 observations of Pc5 waves: Particle flux modulations, J. Geophys. Res., 82, 2774-2786, 1977.

Lam, H.-L. and Rostoker, G.: The relationship of Pc5 micropulsation activity in the morning sector to the auroral westward electrojet, Planet. Space Sci., 26, 473-492, 1978.

Lee, D.-H. and Lysak, R. L.: Magnetospheric ULF wave coupling in the dipole model: The impulsive exitation, J. Geophys. Res., 94, 17 097-17 103, 1989.

Lee, D.-H. and Lyons, L. R.: Geosynchronous magnetic field response to solar wind dynamic pressure pulse, J. Geophys. Res., 109, A04201, doi:10.1029/2003JA010076, 2004.

Mann, I. R., Wright, A. N., Mills, K. J., and Nakariakov, V. M.: Excitation of magnetospheric waveguide modes by magnetosheath flows, J. Geophys. Res., 104, 333-353, 1999.

Mitchell, D. G., Engebretson, M. J., Williams D. J., Cattell C. A., and Lundin, R.: Pc5 pulsations in the outer dawn magnetosphere seen by ISEE 1 and 2, J. Geophys. Res., 95, 967-976, 1990.

Miura, A.: Kelvin-Helmholtz instability at the magnetospheric boundary: Dependence on the magnetosheath sonic Mach number, J. Geophys. Res., 97, 10 665-10 675, 1992.

Nosé, M., Iyemori, T., Sugiura, M., Slavin, A., Hoffman, R. A., Winningham, J. D., and Sato, N.: Electron precipitation accompanying Pc5 pulsations observed by DE satellites and at a ground station, J. Geophys. Res., 103, No. A8, 17 587-17 604, 1998. 
Oberts, P. and Raspopov, O. M.: Study of the Pc5-type geomagnetic pulsations space characteristics, Geomagnetism and Aeronomy, 8 (3), 534-539, 1968.

Pilipenko, V. A., Kleimenova, N. G., Kozyreva, O. V., Yumoto, K., and Bitterly, J.: Longitudinal features of Pc5 pulsations in the morning and evening sectors, Geomagnetism and Aeronomy (English translation), 37 (3), 307-315, 1997.

Poulter, E. M. and Allan, W.: Transient ULF pulsation decay rates observed by ground based magnetometers: The contribution of spatial integration, Planet. Space Sci., 33, 607-616, 1985.

Posch, J. L., Engebretson, M. J., Pilipenko, V. A., Hughes, W. J., Russell, C. T., and Lanzerotti, L. J.: Characterizing the longperiod ULF response to magnetic storms, J. Geophys. Res., 108(A1), 1029, doi:10.1029/2002JA009386, 2003.

Rostoker, G. and Lam, H.-L.: A generation mechanism for Pc 5 micropulsations in the morning sector, Planet. Space Sci., 26, 493-505, 1978.
Rostoker, G., Spadinger, I., and Samson, J. C.: Local time variations in the response of Pc5 pulsations in the morning sector to substorm expansive phase onsets near midnight, J. Geophys. Res., 89, 6749-6757, 1984.

Samson, J. C., Harrold, B. G, Ruohoniemi, J. M., Greenwald, R. A., and Walker, A. D. M.: Field line resonances associated with MHD waveguides in the magnetosphere, Geophys. Res. Lett., 19, 19441-19444, 1992.

Stephenson, J. A. E. and Walker, A. D. M.: HF radar observations of Pc5 ULF pulsations driven by the solar wind, Geophys. Res. Lett., 29, No. 9, doi:10.1029/2001GL014291, 2002.

Walker, A. D. M., Ruohoniemi, J. M., Baker, K. B., Greenwald, R. A., and Samson, J. C.: Spatial and temporal behaviour of ULF pulsations observed by the Goose Bay HF radar, J. Geophys. Res., 97, 12 187-12 202, 1992.

Ziesolleck, C. W. S. and McDiarmid, D. R.: Statistical survey of auroral latitude Pc5 spectral and polarization characteristics, J. Geophys. Res., 100, A10, 19299-19312, 1995. 